\title{
Estimation of Caffeine Intake from Coffee Made From Mixture of Coffee Leaf and Spices
}

\author{
Yitayal A.A 1* $^{*}$ and Tilahun R.D ${ }^{2}$ \\ ${ }^{1}$ Department of Chemistry, College of Natural and Computational Sciences, Mizan-Tepi University, \\ P.O.Box: 121, Tepi, Ethiopia \\ ${ }^{21}$ Department of Biology, College of Natural and Computational Sciences, Mizan-Tepi University, \\ P.O.Box: 121, Tepi, Ethiopia
}

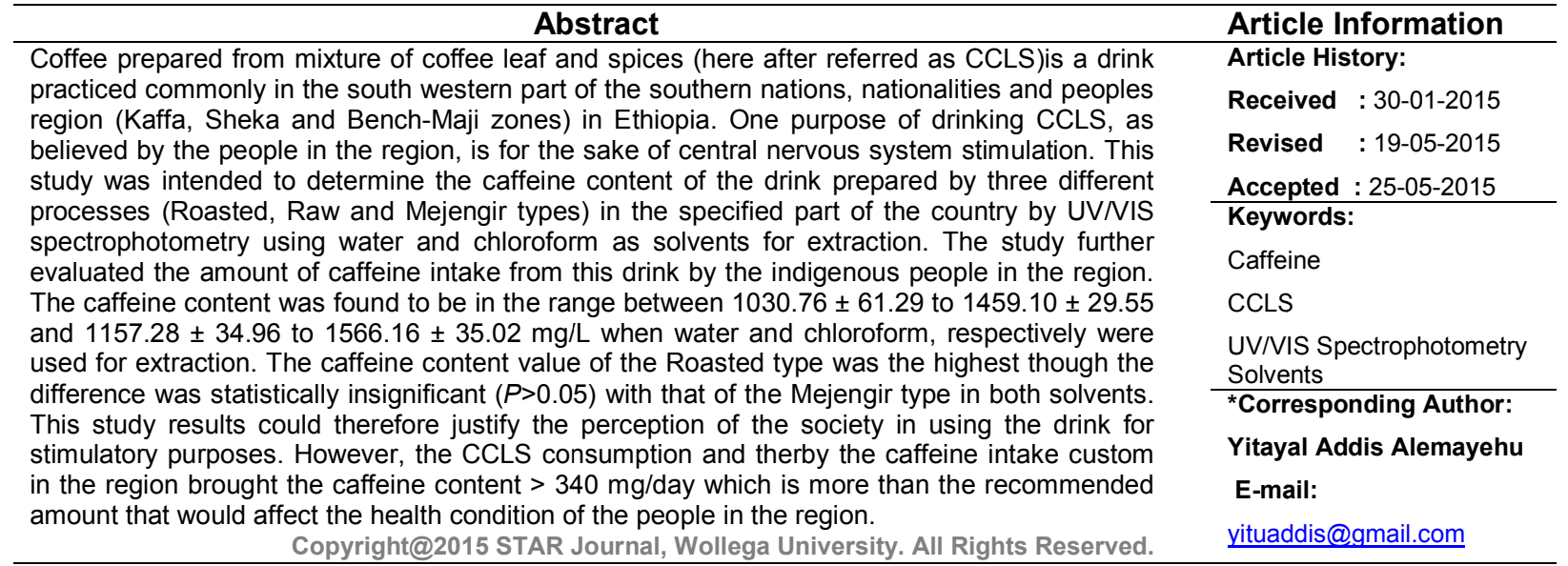

\section{INTRODUCTION}

Caffeine (1, 3, 5-trimethylxanthine), a nervous system stimulant, belongs to a large class of organic compounds called alkaloids. It is naturally present in coffee and is incorporated into many non-alcoholic beverages. Caffeine is found in the leaves, seeds and/or fruits of at least 63 plant species worldwide. Among these the most commonly known sources of caffeine are coffee, cocoa beans, kola nuts and tea leaves (Wanyika et al., 2010).

Coffee is often consumed for its stimulatory effects as caffeine is the most prominent in its composition and it is reported that $70 \%$ of caffeine comes from coffee while soft drinks and tea contribute $16 \%$ and $12 \%$, respectively (Butt and Sultan, 2011). Coffee beans contain between 0.8 and $2.8 \%$ caffeine, depending on species and origin, and it contributes to 10 to $30 \%$ of the bitter taste of coffee brews (Phan et al., 2012). So, Wanyika et al. (2010) reported coffee bean, from which coffee is brewed as the world's primary source of caffeine.

Ethiopia is the birth place of the Arabica coffee tree (MOT, 2012) as it originated from montane forests in south and southwest Ethiopia which form part of Eastern Afromontane biodiversity hotspot region (Wiersum et al., 2007). Coffee is vital to the cultural and socio-economic life as it sustains the livelihood for over 15 million people; provides considerable income from casual labor for many poor rural people and contributes more than $25 \%$ of the country's foreign exchange earnings (MOT, 2012). Due to these reasons; Petit (2007) reported coffee as the back bone of the nation's economy.

A socio-cultural survey in the south western part of Ethiopia revealed that coffee is prepared not only from coffee bean but also from mixture of coffee leaf and spices (Yitayal and Achame, 2014). In the study it is reported that about $50 \%$ of the composition is coffee leaf and the other $50 \%$, excluding water, is the sum of the spices: Ocimum basilicum, Mentha Piperita, Ruta chalepensis, Coriandrum sativum, Lippia Javanica, Allium sativum, Anethum foeniculum, Zingiber officinale, Capsicum annuum, Aframomum corrorima, Allium cepa and salt (sodium chloride). The report indicated that coffee made from coffee leaf and spices (CCLS) can be prepared in three processes called Roasted, Raw and Mejengir types (Yitayal and Achame, 2014). The findings of the socio-cultural study also pointed that one purpose of drinking CCLS is due to its considerable stimulatory effect (Yitayal and Achame, 2014), but its caffeine content is not yet determined quantitatively. 
Yitayal and Tilahun

The objective of this study was therefore; to determine the caffeine content of CCLS prepared in the aforementioned three processes and then compare the results obtained from these three processes one another and with the recommended caffeine intake from the literature.

\section{MATERIALS AND METHODS}

\section{Amount of CCLS Intake}

Semi-structured interview, critical participant observation and on site volume measurement were the instruments applied to collect data on the amount consumed for the three types of CCLS in the sampled areas: Gesha (Damo and Yofo Kebeles) and Gimbo (Mision sefer) in Kaffa zone, Yeki woreda (Addisalem Kebele for Mejengir participants and Kobito Kebeles) in Sheka zone and Aman (Shishika Kebele) and Shay Bench (Kashita Kebele) in Bench-Maji zone.

\section{Experimental \\ Caffeine Determination}

The caffeine content in CCLS was determined by UV/Vis Spectrophotometry by combining the procedures followed by Suteerapataranon (2010), Wanyika et al. (2010) and Maidon et al. (2012). For the extraction of the caffeine from CCLS two solvents were used, water and chloroform. The former was used as the society uses water for CCLS preparation thereby indicate the concentration of caffeine that would commonly available in CCLS drinks prepared by the three processes and might differ based on the boiling time, and the latter was chosen to determine the maximum possible caffeine concentration available in CCLS as chloroform is the best selective solvent due to its polarity properties and good ability to dissolve caffeine (Maidon et al., 2012).

\section{Materials}

The ingredients: leaves of Coffea Arabica, Ocimum basilicum, Mentha Piperita, Ruta chalepensis, Coriandrum sativum, Lippia Javanica, Anethum foeniculum, Zingiber officinale, Capsicum annuum, Aframomum corrorima were collected from the garden of selected three women who have the experience of preparing three different types of CCLS (one woman for one type of CCLS). Allium sativum, Allium cepa and salt (sodium chloride) were purchased from TEPI MARKET.

\section{Chemicals}

Lead (II) acetate, hydrochloric acid and sulfuric acid (all obtained from Sigma-Aldrick (UK) through Mizan-Tepi University, Ethiopia) were employed to remove tannins which could interfere with the analysis by spectrophotometry (Suteerapataranon et al., 2009). In addition, pure caffeine (99.6\%) also obtained from SigmaAldrick (UK) through Jimma University, Ethiopia was used as a standard.

\section{Calibration Standards}

1000 ppm caffeine stock solution was prepared by dissolving $100 \mathrm{mg}$ of pure caffeine in $100 \mathrm{ml}$ of distilled water. 5, 10, 15 and $20 \mathrm{ppm}$ caffeine working solutions were prepared by serial dilution of the stock in $25 \mathrm{ml}$ volumetric flasks with addition of $1.0 \mathrm{ml}$ hydrochloric acid before topping to the mark with distilled water.
Sci. Technol. Arts Res. J., April-June 2015, 4(2): 211-214

\section{Sample Preparation and Determination}

Following the processes and proportions used by the indigenous people, Kaffa, Sheka and Bench-Maji in Ethiopia, each of the three types of CCLS were prepared separately by adding $87.65 \mathrm{~g}$ raw leaf $(22.92 \mathrm{~g}$ in dry weight basis), $32.15 \mathrm{~g}$ roasted leaf $(26.77 \mathrm{~g}$ in dry weight basis) and other $36.61 \mathrm{~g}$ roasted leaf (31.22 $\mathrm{g}$ in dry weight basis) per litre of water for the preparation of the Raw, Roasted and Mejengir type CCLS, respectively. 0.5 $\mathrm{ml}$ of each of CCLS samples were accurately measured and dissolved in water and made to the net volume of 40 $\mathrm{ml}$ with distilled water as sample solution. The sample solution was pipetted to $250 \mathrm{ml}$ flask and $15 \mathrm{ml} 0.01 \mathrm{~mol} / \mathrm{L}$ hydrochloric acid; $3 \mathrm{ml}$ of $2 \mathrm{M}$ basic lead acetate solution was then added and made to the mark with distilled water, shaken up and filtered to clarify. $50 \mathrm{ml}$ filtered solution was pipetted and added to $100 \mathrm{ml}$ flask, $0.3 \mathrm{ml}$ of $5 \mathrm{M}$ sulphuric acid was added and again made to the net volume with distilled water, shaken up and filtered. The absorbance of the working standards and samples were measured on a UV/Vis spectrophotometer (T-80) at 273 $\mathrm{nm}$ using $10 \mathrm{~mm}$ quartz quvette. The distilled (deionized) water was used as a blank and the caffeine level of the samples were calculated from the regression equation of the best line of fit of the standards. The test was done in triplicate and the same process was repeated for chloroform. The reason for the selection of the method was due to UV/Vis spectrophotometer availability in most laboratories, being simple and fast.

\section{Data Analysis}

The caffeine content values obtained from the three processes of CCLS preparation were compared using SPSS version 20 software. Data collected were analyzed by ANOVA, while significant differences among the mean were determined using least significant difference (LSD) multiple comparison test and results were considered statistically at $P<0.05$. The results were then presented as mean \pm SD

\section{RESULTS AND DISCUSSION}

The caffeine contents in Roasted, Raw and Mejengir types of CCLS in water and chloroform were studied. The results showed that each type of CCLS contains considerable caffeine and the Roasted type of CCLS contained the highest concentration of caffeine followed by the Mejengir type (Table 1).

The results of caffeine content of this study was significantly higher than the caffeine contents of coffee infusions which ranges from $20.00 \pm 0.360$ to $53.00 \pm$ $0.300 \mathrm{mg} / \mathrm{L}$ (Phan et al., 2012); caffeine concentrations in tea infusions $260.8 \pm 0.81$ and $220.3 \pm 5.55 \mathrm{mg} / \mathrm{L}$ for ground and non-ground samples, respectively (Suteerapataranon et al., 2009); and Coca cola $170 \mathrm{mg} / \mathrm{L}$ and Pepsi cola $180 \mathrm{mg} / \mathrm{L}$ indicated in jenway. However, the current study results were in agreement with the study on two coffee samples which are $1571.47 \pm 2.53$ and $1528.54 \pm 5.05 \mathrm{mg} / \mathrm{L}$ and significantly lower than study results of tea valued as $3196.46 \pm 11.01 \mathrm{mg} / \mathrm{L}$ as reported by Wanyika et al. (2010), and black tea and green tea values of 24,700 and $34,500 \mathrm{mg} / \mathrm{L}$ in chloroform, respectively (Komes et al., 2009). Generally, the caffeine content of CCLS was comparable to other caffeine rich liquors. 
Table 1: Caffeine content of CCLS in water and chloroform solvents

\begin{tabular}{ccccc}
\hline \multirow{2}{*}{ CCLS Types } & \multicolumn{2}{c}{ Water as a solvent } & \multicolumn{2}{c}{ Chloroform as a solvent } \\
\cline { 2 - 5 } & $\begin{array}{c}\text { Caffeine content } \\
(\mathbf{m g} / \mathbf{L})\end{array}$ & $\begin{array}{c}\text { Regression } \\
\text { Equation }\end{array}$ & $\begin{array}{c}\text { Caffeine content } \\
(\mathbf{m g} / \mathbf{L})\end{array}$ & $\begin{array}{c}\text { Regression } \\
\text { Equation }\end{array}$ \\
\hline $\begin{array}{c}\text { Roasted } \\
\text { CCLS }\end{array}$ & $1491.05 \pm 11.00$ & $0.0338 x+0.18$ & $1566.16 \pm 35.02$ & $0.026 x+0.42$ \\
$\begin{array}{c}\text { Raw CCLS } \\
\text { Mejengir } \\
\text { CCLS }\end{array}$ & $1030.76 \pm 61.29$ & $0.0335 x+0.19$ & $1157.28 \pm 34.96$ & $0.025 x+0.39$ \\
\hline & $1459.10 \pm 29.55$ & $0.0332 x+0.13$ & $1526.61 \pm 14.16$ & $0.024 x+0.41$ \\
\hline
\end{tabular}

The difference of the caffeine contents of the roasted type with that of the Raw one is statistically significant
$(P<0.05)$, but insignificant $(P>0.05)$ with that of the Mejengir type of CCLS type as shown in Table 2.

Table 2: Multiple comparisons (LSD) for caffeine content of CCLS types in two solvents

\begin{tabular}{|c|c|c|c|c|c|c|c|}
\hline \multirow[t]{2}{*}{$\begin{array}{c}\text { Dependent } \\
\text { Variable }\end{array}$} & \multirow[t]{2}{*}{$\begin{array}{l}\text { (I)Types of } \\
\text { CCLS }\end{array}$} & \multirow[t]{2}{*}{$\begin{array}{l}\text { (J)Types of } \\
\text { CCLS }\end{array}$} & \multirow[t]{2}{*}{$\begin{array}{c}\text { Mean } \\
\text { Difference } \\
(\mathrm{I}-\mathrm{J})\end{array}$} & \multirow[t]{2}{*}{ Std. Error } & \multirow[t]{2}{*}{ Sig. } & \multicolumn{2}{|c|}{$\begin{array}{l}95 \% \text { Confidence } \\
\text { Interval }\end{array}$} \\
\hline & & & & & & $\begin{array}{l}\text { Lower } \\
\text { Bound }\end{array}$ & $\begin{array}{l}\text { Upper } \\
\text { Bound }\end{array}$ \\
\hline \multirow{6}{*}{$\begin{array}{l}\text { Water as a } \\
\text { solvent }\end{array}$} & \multirow[t]{2}{*}{ Roasted CCLS } & Raw CCLS & $555.75000^{*}$ & 36.38389 & 0.000 & 466.7218 & 644.7782 \\
\hline & & $\begin{array}{l}\text { Mejengir } \\
\text { CCLS }\end{array}$ & 27.40667 & 36.38389 & 0.480 & -61.6215 & 116.4348 \\
\hline & \multirow[t]{2}{*}{ Raw CCLS } & Roasted CCLS & $-555.75000^{*}$ & 36.38389 & 0.000 & -644.7782 & -466.7218 \\
\hline & & $\begin{array}{l}\text { Mejengir } \\
\text { CCLS }\end{array}$ & $-528.34333^{*}$ & 36.38389 & 0.000 & -617.3715 & -439.3152 \\
\hline & \multirow[t]{2}{*}{ Mejengir CCLS } & Roasted CCLS & -27.40667 & 36.38389 & 0.480 & -116.4348 & 61.6215 \\
\hline & & Raw CCLS & $528.34333^{*}$ & 36.38389 & 0.000 & 439.3152 & 617.3715 \\
\hline \multirow{6}{*}{$\begin{array}{c}\text { Chloroform as a } \\
\text { solvent }\end{array}$} & \multirow[t]{2}{*}{ Roasted CCLS } & Raw CCLS & $608.88333^{*}$ & 73.76194 & 0.000 & 428.3944 & 789.3723 \\
\hline & & $\begin{array}{l}\text { Mejengir } \\
\text { CCLS }\end{array}$ & $39.54667^{*}$ & 73.76194 & 0.611 & -140.9423 & 220.0356 \\
\hline & \multirow[t]{2}{*}{ Raw CCLS } & Roasted CCLS & $-608.88333^{*}$ & 73.76194 & 0.000 & -789.3723 & -428.3944 \\
\hline & & $\begin{array}{c}\text { Mejengir } \\
\text { CCLS }\end{array}$ & $-569.33667^{*}$ & 73.76194 & 0.000 & -749.8256 & -388.8477 \\
\hline & \multirow[t]{2}{*}{ Mejengir CCLS } & Roasted CCLS & $-39.54667^{*}$ & 73.76194 & 0.611 & -220.0356 & 140.9423 \\
\hline & & Raw CCLS & $569.33667^{*}$ & 73.76194 & 0.000 & 388.8477 & 749.8256 \\
\hline
\end{tabular}

* The mean difference is significant at the .05 level; SD: Least significant Difference

One reason could be the larger mass of the coffee leaf (dry weight basis) that was taken in the Roasted type. In the Raw type case the mass of the water in the coffee leaf was considered as the mass of the coffee leaf alone which could minimize the net content of the coffee leaf (i.e. the mass of the coffee leaf in dry weight basis was only $22.92 \mathrm{~g}$ per liter of water). Second, roasting to optimal temperature could increase caffeine yield as reported for the coffee bean where green coffee been was compared with the roasted one (Alemayehu, 2007 unpublished). Moreover, the Roasted and Mejengir types were similar in the type of coffee leaf used (i.e. both used roasted and dried form) so that the net mass of the coffee leaf was higher relative to the Raw type CCLS.

The caffeine contents of the CCLS types when chloroform was used were higher than the contents when water was used (Table 1). This indicated that the society could utilize the caffeine content in the second and third rounds of the drink as water would not extract the full content at a time and depends on the time and temperature given for boiling (Phan et al., 2012). This in part could justify why the community drink the second and third round CCLS prepared for a single ceremony. The least significant difference (LSD) test result showed that the difference within the Roasted CCLS of the two solvents and the Mejengir type CCLS is significant $(p<0.05)$ (Table 2), and insignificant for the Raw one.
Though the caffeine content of CCLS was comparable to other caffeine rich beverages, the amount of CCLS daily consumed by the society was so high that the commulative caffeine intake could reach to the level that would affect its health. The survey result on the daily CCLS consumption show that , the CCLS consumption of the indigenous people ranges from 295 to 330,420 to 520 and 530 to $584 \mathrm{ml}$ for children, teenagers and adults, respectively (Table 3 ).

The Roasted type of CCLS was found to provide the maximum amount of caffeine daily consumed which was 447,626 and $790 \mathrm{mg} /$ day for the different age groups, respectively. It is reported, in other studies, that the moderate daily consumption of up to $400 \mathrm{mg}$ of caffeine has been considered safe for healthy adults and nonpregnant/non-lactating women (Nawrot et al., 2003) and caffeine in moderate doses up to $300 \mathrm{mg}$ can improve cognitive performance in rested, sleep-deprived, and fatigued individuals (Lieberman et al.,2002) which is half and only one-third of this study results, respectively. Moreover, doses of caffeine over $600 \mathrm{mg} /$ day can cause significant side effects including tachycardia, tremors, insomnia, nervousness, upset, chest pain, and arrhythmias (Lieberman et al., 2002). In addition, moderate caffeine consumption for most individuals, including sensitive populations such as pregnant women and children, is about $200 \mathrm{mg}$ per day (Nour et al., 2010) 
Table 3: CCLS and caffeine consumption rate by the indigenous people

\begin{tabular}{lccc}
\hline Types of CCLS & Age Groups (year) & $\begin{array}{c}\text { Daily intakes } \\
\text { of CCLS (ml) }\end{array}$ & $\begin{array}{c}\text { Daily intakes of caffeine } \\
\text { from CCLS (mg)* }\end{array}$ \\
\hline \multirow{2}{*}{ Roasted CCLS } & $5-10$ & $300 \pm 13$ & 447 \\
& $11-18$ & $420 \pm 18$ & 626 \\
& 19 and above & $530 \pm 23$ & 790 \\
Raw CCLS & $5-10$ & $330 \pm 12$ & 340 \\
& $11-18$ & $520 \pm 27$ & 536 \\
& 19 and above & $570 \pm 29$ & 587 \\
Mejengir CCLS & $5-10$ & $295 \pm 11$ & 431 \\
& $11-18$ & $414 \pm 16$ & 604 \\
& 19 and above & $527 \pm 27$ & 768 \\
\hline
\end{tabular}

which is by far lower than $447 \mathrm{mg} /$ day. Generally, the results of this study revealed that the daily caffeine intake from CCLS alone was more than $600 \mathrm{mg}$ for adults except the Raw type of CCLS users. Together with CCLS, the society would consume other caffeine source beverages especially coffee there by maximize the total caffeine intake and would exacerbate the side effects of caffeine in the region. Therefore, CCLS users should minimize the amount intake to adequate levels (up to 250 to 400 $\mathrm{ml} /$ day) except for children, non-pregnant and nonlactating women who require caffeine below $200 \mathrm{ml} / \mathrm{day}$.

\section{CONCLUSION}

One purpose of drinking coffee made from coffee leaf and spices by the people in the south western part of the southern nations nationalities and peoples region (Kaffa, Sheka and Bench-Maji zones) in Ethiopia is for its stimulatory effect. This study could assure the indigenous people perception and practice on CCLS use as central nervous system stimulation because CCLS was found to contain considerable amounts of caffeine (especially the Roasted one). CCLS is therefore a drink that could be used as an alternative for coffee and other caffeine source liquors to provide caffeine for the rest of the people in and out of Ethiopia. Using CCLS more than $300 \mathrm{ml} /$ day (more than the adequate caffeine in it) should be lowered to avoid its side effects.

\section{Acknowledgents}

This manuscript is based on the work supported by Mizan-Tepi University. The author would like to acknowledge this institution and the contributions of the following individuals: Tibka Demissie, Jemayinesh Teka, Abel Mandefro, Emebet Abere, Zelalem Kibret, Sefowdin Berta, Yimam Getinet and Temesgen Hailu.

\section{Conflict of Interest}

Conflict of interest none declared.

\section{REFERENCES}

Alemayehu, K.E. (2007). Investigation on effects of roasting temperature and roasting time on caffeine content in coffee using optical method. MSc thesis, Addis Ababa University, Addis Ababa, Ethiopia. Pp 54.

Butt, M.S., Sultan, M.T. (2011). Coffee and its consumption: benefits and risks. Critical Reviews in Food Science and Nutrition 51: 363-373.

Federal Democratic Republic of Ethiopia; Ministry of Trade (MOT) (2012). Coffee Opportunities in Ethiopia. Addis Ababa, Ethiopia. Accessed on November 20, 2013. Available from: http://www.eafca.org/wwc/downloads IAFCCE09/presentation/coffee opportunities.
JENWAY. The quantitative determination of caffeine in beverages and soft drinks using UV wavelength spectroscopy. Application note: A09-010A; 73 series spectrophotometer. Accessed on November 20, 2013. Available from: www.jenway.com.

Komes, D., Horžić, D., Belščak, A., Ganič, K.K., Baljak, A. (2009). Determination of caffeine content in tea and maté tea by using different methods. Czech Journal of Food Sciences 27: S213-S216.

Lieberman, H.R., Tharion, W.J., Shukitt-Hale, B., Speckman, K.L. (2002). Effects of caffeine, sleep loss, and stress on cognitive performance and mood during U.S. Navy SEAL training. Psychopharmacology 164(3): 250-61.

Maidon, B.M., Mansoer, A.O., Sulistyarti, H. (2012). Study of Various Solvents for Caffeine: Determination Using Uv Spectrophotometeric. Journal of Applied Sciences Research 8(5): 2439-2442.

Nawrot, P., Jordan, S., Eastwood, J., Rotstein, J. (2003). Effects of caffeine on human health. Food Additives and Contaminants Part A. Chemistry Analysis Control Exposure and Risk Assessment 20(1):1-30.

Nour, V., Trandafir, I., Ionică, M.E. (2010). Chromatographic determination of caffeine contents in soft and energy drinks available on the Romanian market. Scientific Study \& Research; Chemistry and Chemical Engineering, Biotechnology, Food Industry 11(3):351-358.

Petit, N. (2007). Ethiopia's Coffee Sector: A Bitter or Better Future. Journal of Agrarian Change 7(2):225-263.

Phan, T.D., Kuban, Kráčmar, S. (2012). Determination of caffeine contents of coffee brands in the Vietnamese market. Journal of Microbiology, Biotechnology and Food Sciences 1: 995-1002.

Suteerapataranon, S., Butsoongnern, J., Punturat, P., Jorpalit, W., Thanomsilp, C. (2009). Caffeine in Chiang Rai tea infusions: Effects of tea variety, type, leaf form, and infusion conditions. Journal of Food Chemistry 114:1335-1338.

Wanyika, H.N., Gatebe, E.G., Gitu, L.M., Ngumba, E.K., Maritim, C.W. (2010). Determination of caffeine content of tea and instant coffee brands found in the Kenyan market. African Journal of Food Science 4(6): 353-358.

Wiersum, K.F., Gole, T.W., Gatzweiler, F., Volkmann, J., Bognetteau, E., Wirtu, O. (2008). Certification of wild coffee in Ethiopia; Experiences and challenges (Article submitted to Forests, Trees and Livelihoods April, 2007). Research Gate, DOI: 10.1080/14728028.2008.9752614.

Yitayal, A.A., Achame, H.A. (2014). Socio-cultural practice on coffee made from mixtures of coffee leaf and spices. International multidisciplinary e-journal (IMEJ) 3(6):36-45. 